\title{
Screening a novel FGF3 antagonist peptide with anti-tumor effects on breast cancer from a phage display library
}

\author{
WEI WANG ${ }^{1 *}$, TAO CHEN $^{2 *}$, HAICHENG LI $^{2}$, YUHUI CHEN ${ }^{2}$, ZHILONG WU $^{1}$, TONGMING FENG ${ }^{1}$, \\ XILIN ZHANG ${ }^{1}$, QIU ZHONG ${ }^{2}$, QIANHONG ZHONG ${ }^{1}$, GUOZHOU LI $^{3}$, LINA GUO $^{4}$, LIN ZHOU $^{2}$ and JIE ZHOU ${ }^{1}$ \\ ${ }^{1}$ Department of Clinical Laboratory and Disease Control, Foshan Fourth People's Hospital, Foshan, Guangdong 528000; \\ ${ }^{2}$ Department of Provincial Reference Laboratory and Disease Control, Center for Tuberculosis Control of Guangdong, \\ Guangzhou, Guangdong 510630; ${ }^{3}$ Department of Clinical Laboratory, Chronic Disease Control and Prevention Station of Dongguan, \\ Dongguan, Guangdong 523008; ${ }^{4}$ Department of Nutrition, Guangdong Provincial Hospital of Chinese Traditional Medicine, \\ Guangzhou, Guangdong 510120, P.R. China
}

Received November 16, 2014; Accepted August 4, 2015

DOI: $10.3892 / \mathrm{mmr} .2015 .4248$

\begin{abstract}
Accumulating evidence has suggested that fibroblast growth factor 3 (FGF3) is expressed in breast cancer and correlates with the stage and grade of the disease. In the present study, a specific FGF3-binding peptide (VLWLKNR, termed FP16) was isolated from a phage display heptapeptide library with FGF3. The peptide FP16 contained four identical (WLKN) amino acids and demonstrated high homology to the peptides of the 188-194 (TMRWLKN) site of the high-affinity FGF3 receptor fibroblast growth factor receptor 2. Functional analyses indicated that FP16 mediated significant inhibition of FGF3-induced cell proliferation, arrested the cell cycle at the $\mathrm{G} 0 / \mathrm{G} 1$ phase by increasing proliferation-associated protein $2 \mathrm{G} 4$, suppressing cyclin D1 and proliferating cell nuclear antigen, and inhibited the FGF3-induced activation of extracellular signal-regulated kinase $1 / 2$ and Akt kinase. Taken together, these results demonstrated that the peptide FP16, acting as an FGF3 antagonist, is a promising therapeutic agent for the treatment of breast cancer.
\end{abstract}

Correspondence to: Dr Lin Zhou, Department of Provincial Reference Laboratory and Disease Control, Center for Tuberculosis Control of Guangdong, 485 Huangpu Street, Guangzhou, Guangdong 510630, P.R. China

E-mail: 13332864810@vip.163.com

Dr Jie Zhou, Department of Clinical Laboratory and Disease Control, Foshan Fourth People's Hospital, 106 Jin Lan Road, Foshan, Guangdong 528000, P.R. China

E-mail: zhoujiefstb@163.com

*Contributed equally

Key words: fibroblast growth factor 3, phage display, proliferation, cell cycle, breast cancer

\section{Introduction}

Fibroblast growth factor 3 (FGF3), belonging to the family of fibroblast growth factors (FGFs), regulates several developmental processes, including brain patterning, branching morphogenesis and limb development, by binding, dimerizing and activating cell surface FGF receptors (FGFRs) (1). The extra-cellular ligand-binding portion of FGFRs is composed of three immunoglobulin-like (Ig-like) domains (D1-D3). The crystal structure of the ectodomain of the FGFR complex with FGF demonstrated that the ligand-binding domain of FGFR involves Ig-like domains II and III (D2 and D3, respectively), as well as the linker between D2 and D3 (2). It has been reported that FGF3/FGFRs are associated with multiple biological activities, including cellular proliferation, differentiation, invasiveness and motility, thus demonstrating the potential to initiate and promote tumorigenesis (3).

Breast cancer is one of the most common types of malignancy in females and the second most common cause of cancer-associated mortality in females worldwide $(4,5)$. The literature devoted to prognostic factors for breast cancer is extensive (6-8). Histology, tumor stage and lymph-node status are now supplemented with measurements of ploidy, steroid hormone receptors, S-phase fractions, growth factors, oncogenes and oncogene products (9). Even though significant progress has been achieved in developing early diagnosis and treatment, acquired resistance to current chemotherapies and failure of endocrine-targeted therapy in certain patients have resulted in a great clinical requirement for new therapeutic agents for breast cancer. The expression and associated amplification of FGF3 and FGFRs have been identified in breast cancer (10), and they correlate with advanced-stage and high-grade tumors, as well as decreased patient survival time (11). Therefore, it is likely that the development of antagonists targeting FGF3 and its receptors is a strategy that may assist in overcoming resistance to current chemotherapy and endocrine-targeted therapy. In the present study, a high affinity FGF3-binding peptide was isolated from a phage display library and the functions of the isolated peptide were 
further investigated to evaluate its possible therapeutic potential in breast cancer.

\section{Materials and methods}

Cell lines and reagents. The cell lines MDA-MB-231, T47D and Cos-7 were purchased from the Type Culture Collection of the Chinese Academy of Sciences (Shanghai, China). They were all maintained at $37^{\circ} \mathrm{C}$ in a humidified atmosphere of $5 \% \mathrm{CO}_{2}$ and cultured in Dulbecco's modified Eagle's medium (DMEM) supplemented with $10 \%$ (v/v) fetal bovine serum (FBS; Guangzhou Ruite Bio-tec Co., Ltd., Guangzhou, China). The Ph.D.- $7^{\text {TM }}$ Phage Display Peptide Library kit and Escherichia coli ER2738 were purchased from New-England Biolabs (Ipswich, MA, USA). Recombinant human FGF3 was obtained from Uscn Life Science, Inc. (Export Processing Zone, Economic and Technological Development Zone, Wuhan, China). The mouse horseradish peroxidase (HRP) anti-M13 monoclonal antibody (cat. no. 27-9421-01; $1: 5,000)$ was a product of GE Healthcare (Piscataway, NJ, USA). Cell Signaling Technology Inc., (Danvers, MA, USA) provided the monoclonal rabbit anti-phospho Erk1/2 (cat. no. 4370s; 1:2,000), monoclonal rabbit anti-Erk1/2 (cat. no. 9194s; 1:2,000), monoclonal rabbit anti-phospho Akt (cat. no. 13038s; 1:1,000), monoclonal rabbit anti-Akt (cat. no. 4685s; 1:1,000), monoclonal rabbit anti-cyclin D1 (cat. no. 2978s; 1:1,000), monoclonal rabbit anti-proliferating cell nuclear antigen (PCNA; cat. no. 13110s; 1:1,000) and the monoclonal rabbit anti-GAPDH antibodies (cat. no. 3907s; 1:1,000). The monoclonal rabbit anti-proliferation associated protein 2G4 (PA2G4; cat. no. sc-292466; 1:1,000) was from Santa Cruz Biotechnology, Inc. (Santa Cruz, CA, USA). The goat-anti-rabbit secondary (cat. no. sc-2054; 1:1,000), and goat-anti-mouse secondary (cat. no. sc-2005; 1:1,000) antibodies were obtained from Santa Cruz Biotechnology, Inc.

In vitro phage-display biopanning. The 96-well microliter plates were coated with $10 \mu \mathrm{g} / \mathrm{ml} \mathrm{FGF3} \mathrm{in} \mathrm{sodium} \mathrm{carbonate}$ buffer $\left(0.1 \mathrm{M} \mathrm{NaHCO}_{3}, \mathrm{pH} 8.6\right)$ at $4^{\circ} \mathrm{C}$ overnight, followed by blocking with bovine serum albumin (BSA) in Tris-buffered saline (TBS) for $2 \mathrm{~h}$ at $37^{\circ} \mathrm{C}$ and washing six times with $0.05 \%$ Tween-20 in TBS (0.05\% TBST). Subsequently, $10 \mu$ l of diluted original library $2 \times 10^{11}$ plaque-forming units (pfus) with $100 \mu \mathrm{l}$ TBST was added to the coated well. Following incubation for $2 \mathrm{~h}$ at room temperature, the plates were washed with $0.05 \%$ TBST. The bound phages were eluted with $100 \mu 1$ of $0.1 \mathrm{M}$ glycine-HCl buffer ( $\mathrm{pH}$ 2.2) and were then neutralized by $15 \mu \mathrm{l}$ of $1 \mathrm{M}$ Tris- $\mathrm{HCl}$ ( $\mathrm{pH} 9.1$ ). The eluted phages were amplified by propagation in E. coli ER2738, purified and concentrated with polyethylene glycol/ $\mathrm{NaCl}$, and titrated as described in the standard protocol (NEB). Three additional rounds of selection were performed under more stringent conditions. Briefly, the concentration and incubation time of FGF3 was gradually reduced $(5 \mu \mathrm{g}$ for $1.5 \mathrm{~h}, 2.5 \mu \mathrm{g}$ for $1 \mathrm{~h}, 1.25 \mu \mathrm{g}$ for $0.5 \mathrm{~h}$ in the 2nd, 3rd and 4th round, respectively), and the concentration of Tween-20 was gradually increased $(0.1,0.3,0.5 \%$ for the $2 \mathrm{nd}$, 3 rd and 4th round, respectively).

Identification of positive phage clones by enzyme-linked immunosorbent assay (ELISA). The 96-well plates were coated at $4^{\circ} \mathrm{C}$ overnight with FGF3 and blocked with $300 \mu$ l blocking buffer (5\% BSA) for $2 \mathrm{~h}$ at $4^{\circ} \mathrm{C}$. The wells coated without FGF3 with blocking buffer were used as the negative control. Following washing with $0.05 \%$ TBST six times, phage clones $\left(10^{10} \mathrm{pfu} /\right.$ well $)$ were added and incubated for $1 \mathrm{~h}$ with gentle agitation at room temperature. The plates were washed with TBST, then incubated with $200 \mu 1$ of HRP-anti-M13 $(1: 5,000)$ for $1 \mathrm{~h}$ and washed again. The plates were developed with the substrate (50 $\mu \mathrm{l} /$ well of 3,3',5,5'-tetramethylbenzidine), terminated by $50 \mu \mathrm{l} /$ well of $2 \mathrm{M} \mathrm{H}_{2} \mathrm{SO}_{4}$ and the absorbance was measured at $450 \mathrm{~nm}$ using a microplate reader (3550; Bio-Rad Laboratories, Inc., Hercules, CA, USA).

DNA sequencing and peptide synthesis. The DNA sequencing was performed by Invitrogen Life Technologies (Shanghai, China) and sequences were analyzed using DNAssist software (version 2.2; Softonic, Barcelona, Spain). Peptide FP16 (VLWLKNR, translated from the selected F16 phage clone DNA sequence) and an irrelevant control ZP8 peptide (RPNPTLS, obtained from another screening strategy) were synthesized by Beijing SBS Genetech Co., Ltd. (Beijing, China).

Cell proliferation assessment. Effects of FP16 on cancer cell viability and proliferation were assessed by a 3-(4,5-dimethylthiazol-2-yl)-2,5-diphenyltetrazolium bromide (MTT; American Type Culture Collection, Rockville, MD, USA) assay. Cells were seeded in 96 -well plates $\left(5 \times 10^{3}\right.$ cells/well) in DMEM with $10 \% \mathrm{FBS}$ at $37^{\circ} \mathrm{C}$ for $24 \mathrm{~h}$. Subsequently, the cells were starved for $24 \mathrm{~h}$ and treated with $50 \mathrm{ng} / \mathrm{ml}$ FGF3 alone or FGF3 plus serially diluted peptides for $48 \mathrm{~h}$. Cells treated with DMEM with $0.4 \%$ FBS alone were used as controls. A total of $20 \mu \mathrm{l}$ of MTT was added to each well and incubated for $4 \mathrm{~h}$. The crystals were dissolved in $150 \mu \mathrm{l}$ dimethyl sulfoxide (DMSO) and the absorbance was measured at $490 \mathrm{~nm}$ with the aforementioned microplate reader.

Flow cytometric analysis of the cell cycle. Cells were seeded in 6 -well plates $\left(3 \times 10^{5}\right.$ cells/well) for $24 \mathrm{~h}$, starved for another $24 \mathrm{~h}$ and treated with $50 \mathrm{ng} / \mathrm{ml}$ FGF3 alone or FGF3 plus serially diluted peptides for $48 \mathrm{~h}$. Cells were collected and fixed in $70 \%$ ice-cold ethanol for $30 \mathrm{~min}$ at $4^{\circ} \mathrm{C}$. Following washing with phosphate-buffered saline (PBS), the cells were stained with propidium iodide (PI) in the dark at room temperature for $30 \mathrm{~min}$. The percentage of cells at various phases of the cell cycle was analyzed using the FlowJo analysis program (FACSCalibur; BD Biosciences, Franklin Lakes, NJ, USA).

Western blot analysis of mitogen-activated protein kinase (MAPK), Akt activation and expression of PA2G4, PCNA and cyclin D1. Cells were seeded in 6 -well plates $\left(4 \times 10^{6}\right.$ cells/well) for $24 \mathrm{~h}$, starved for another $24 \mathrm{~h}$ and treated with serially diluted FP16 for 30 min prior to stimulation with FGF3 for $3 \mathrm{~h}$. Cells were lysed in SDS-PAGE loading buffer following being washed with cold PBS. The samples were separated by $10 \%$ SDS-PAGE and transferred onto a polyvinylidene fluoride membrane $(350 \mathrm{~mA}, 70 \mathrm{~min}$; Sigma-Aldrich, Shanghai, China). The membrane was blocked with $5 \%$ non-fat dry milk in TBS buffer for $1 \mathrm{~h}$ and incubated with 
Table I. Enrichment of phages for each round of selection from the phage display library.

\begin{tabular}{|c|c|c|c|c|c|}
\hline Round & FGF3 $(\mu \mathrm{g})$ & $\begin{array}{l}\text { Concentration of } \\
\text { Tween } 20(\mathrm{v} / \mathrm{v})\end{array}$ & $\begin{array}{l}\text { Input phage } \\
(\mathrm{pfu})\end{array}$ & $\begin{array}{c}\text { Output } \\
\text { phage (pfu) }\end{array}$ & $\begin{array}{c}\text { Recovery } \\
\text { (output/input) }\end{array}$ \\
\hline 1 & 10 & 0.05 & $2.00 \times 10^{11}$ & $7.50 \times 10^{7}$ & $3.75 \times 10^{-4}$ \\
\hline 2 & 5 & 0.10 & $3.50 \times 10^{11}$ & $2.80 \times 10^{8}$ & $8.00 \times 10^{-4}$ \\
\hline 3 & 2.5 & 0.30 & $1.60 \times 10^{11}$ & $8.20 \times 10^{8}$ & $5.13 \times 10^{-3}$ \\
\hline 4 & 1.25 & 0.50 & $1.20 \times 10^{11}$ & $5.60 \times 10^{9}$ & $4.67 \times 10^{-2}$ \\
\hline
\end{tabular}

The recovery efficiency of each round was presented. In each round, the unbound phages were cleared via washing with Tris-buffered saline with Tween 20 and then the bound phages were recovered and amplified in E. coli 2738 for the following round of panning. The output/input ratio was used to determine the phage recovery rate of each round. FGF3, fibroblast growth factor 3; pfu, plaque forming units.

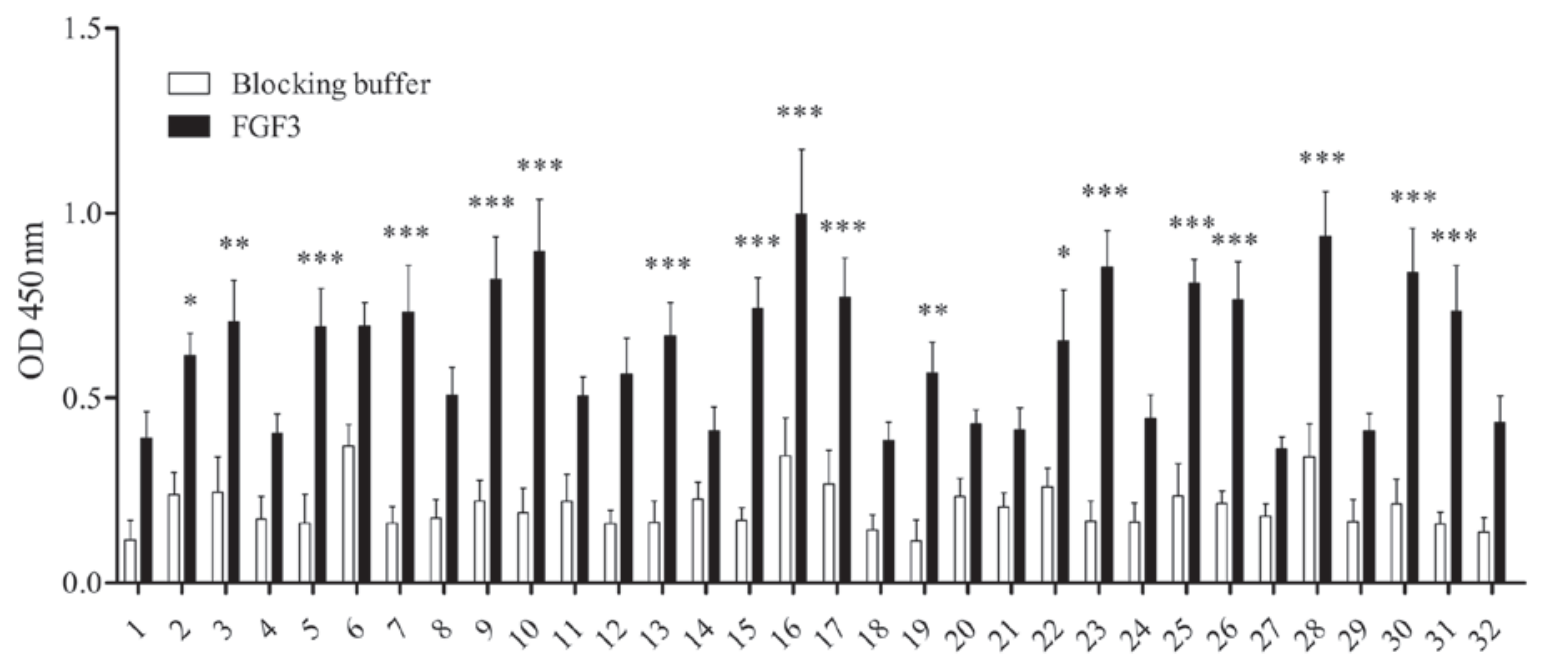

Phage clone number

Figure 1. Appraisal of the binding ability of 32 phage clones by ELISA. Individual 96-well microtitre wells were coated with FGF3 overnight. The blocking buffer without FGF3 was used as a negative control. Approximately $1 \times 10^{11} \mathrm{pfu}$ of phages were added to each well for $1 \mathrm{~h}$ at room temperature. Subsequently, the diluted horseradish peroxidase/anti-M13 monoclonal conjugate was added and incubated for $1 \mathrm{~h}$ at room temperature. An $\mathrm{OD}_{450}$ was obtained following the blocking reaction. Data are presented as the mean \pm standard deviation of triplicate samples. ${ }^{*} \mathrm{P}<0.05,{ }^{* * *} \mathrm{P}<0.01,{ }^{* * * *} \mathrm{P}<0.001$ vs. the blocking buffer sample. FGF3, fibroblast growth factor 3; OD, optical density; pfu, plaque forming units.

the primary antibody (an anti-phospho-Erk1/2 rabbit mAb or an anti-phospho-Akt rabbit $\mathrm{mAb}$ ) overnight at $4^{\circ} \mathrm{C}$, followed by a goat anti-rabbit IgG, HRP-linked antibody $(1: 1,000$ dilution) at room temperature for $1 \mathrm{~h}$. Western blot analysis of PA2G4, cyclin D1 and PCNA expression was performed using the same method, with the following exceptions: To detect PA2G4 and PCNA expression, the starved cells were treated with $50 \mathrm{ng} / \mathrm{ml}$ FGF3 alone or $50 \mathrm{ng} / \mathrm{ml} \mathrm{FGF3} \mathrm{plus}$ $4 \mu \mathrm{M}$ FP16 for $48 \mathrm{~h}$, and to detect cyclin D1 expression, the starved cells were treated with serially diluted FP16 for 30 min prior to stimulation with FGF3 for $6 \mathrm{~h}$.

\section{Results}

In vitro screening. The Ph.D.- $7^{\text {Tм }}$ Phage Display Peptide Library kit was used to isolate high-affinity phages that could specifically bind to FGF3. As shown in Table I, with gradually increased stringency of selection, the recovery rate was 124 -fold higher (between $4.67 \times 10^{-2}$ and $3.75 \times 10^{-4}$ ) following four rounds of screening compared with after the first round, suggesting that the phages specifically bound to FGF3 were successfully enriched.

Identification of the affinity of selected phage clones by ELISA. High-affinity FGF3-binding clones were further identified from the recovered phage clones by ELISA. As shown in Fig. 1, following four rounds of selection, 32 individual phage clones were randomly selected and individually amplified. Of the 32 phage clones, 14 clones exhibited relatively high binding capabilities to FGF3 (clones 5, 7, 9, 10, 13, 15, 16, 17, 23, 25, 26, 28, 30 and 31) compared with the control blocking buffer, and the 16th clone demonstrated the highest, suggesting that it may have a greater affinity for FGF3 than the other clones. Subsequently, these 14 positive phage clones were selected for sequencing.

Sequence analysis and property prediction of positive phages. FGF3 binds to and executes its pleiotropic biological actions in cells expressing FGFR1, FGFR2, FGFR3 or FGFR4. The affinity of FGF3 for binding to FGFR2 is significantly higher 
Table II. Amino acid sequences of specific FGF3-binding peptides compared with FGFR2.

\begin{tabular}{lllccr}
\hline Clone & \multicolumn{1}{c}{ Peptide } & $\begin{array}{c}\text { Sequence } \\
(\text { N-C })^{\mathrm{a}}\end{array}$ & $\begin{array}{c}\text { Similarities to } \\
\text { FGFR2 }_{151-355}\end{array}$ & $\begin{array}{c}\text { Theoretical } \\
\text { PI }\end{array}$ & GRAVY \\
\hline F5 & FP5 & NITPWDT & 0.0049020 & 3.80 & -0.914 \\
F7/13 & FP7 & QPMLKIS & 0.0147059 & 8.75 & 0.057 \\
F9/10/16/23/28/30 & FP16 & VLWLKNR & 0.0147059 & 11.00 & -0.143 \\
F15 & FP15 & ESKVGAP & 0.0098039 & 6.10 & -0.600 \\
F17/26 & FP17 & WLGHRVP & 0.0098039 & 9.76 & -0.371 \\
F25 & FP25 & KEHDPSR & 0.0098039 & 6.75 & -3.010 \\
F31 & FP31 & SQPAWLP & 0.0098039 & 5.24 & -0.400 \\
& FGFR2 2 188-194 & TMRWLKN & & 11.00 & -1.114 \\
& FGFR2 ${ }_{151-355}$ & & & 8.60 & -0.490 \\
\hline
\end{tabular}

Following the four rounds of screening, 14 clones were selected for sequencing and sequences were analyzed by BioEdit and ProtParam

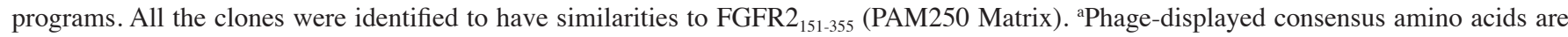
shown in bold. FGF3, fibroblast growth factor 3; FGFR2, fibroblast growth factor receptor 2. GRAVY, grand averages of hydropathicity.

compared with binding to the other three isoforms (2). The crystal structure of the FGF3 complex with FGFR demonstrated that the ligand-binding domains of FGFR involve the highly conserved Ig-like D2 and D3, and the linker region between D2 and D3 (12). Therefore, the amino acid sequences of the selected peptides were compared with the motif (151-355 aa) located at D2-D3 of FGFR2. As shown in Table II, phage clones 16 (FP16) and 7 (FP7) demonstrated the highest sequence similarity to D2-D3 of FGFR2 (0.0147059, PAM250 Matrix). The FP16 peptide (VLWLKNR) contains four (WLKN) amino acids that are identical to the peptides of the 188-194 (TMRWLKN) of FGFR2 (GenBank ID CAA96492.1). In the physiological state, FP16, FGFR $2_{188-194}$ and FGFR $2_{151-355}$ all carry positive charges. In addition, their grand averages of hydropathicity (GRAVY) are all negative. Taken together, these data suggest that the FP16 peptide, sharing four amino acids (WLKN) identical to the ligand-binding motif in D2 of FGFR2, may bind FGF3 via electrostatic interactions and therefore may have the potential to interrupt FGF3 binding to its receptor. Thus, peptide FP16 was selected for further investigation.

FP16 inhibits FGF3-stimulated cell proliferation. Cell lines expressing a high level of FGFRs, including MDA-MB-231 and T47D breast cancer cells, and Cos-7 cells, which do not express FGFRs were used in the study $(13,14)$. The efficacy of the synthetic FP16 peptides in inhibiting FGF3-stimulated tumor cell proliferation was determined by an MTT assay. As shown in Fig. 2, the FP16 peptides inhibited MDA-MB-231 and T47D cell proliferation in a dose-dependent manner, while FP16 had little inhibitory effect on Cos-7 cells that do not express FGF3 receptors.

FP16 arrests FGF3-induced cells at the G0/G1 phase via cyclin D1. PI staining combined with flow cytometric analysis was performed to investigate the effect of FP16 on the cell-cycle progression of MDA-MB-231 and T47D cells induced by FGF3. As shown in Fig. 3, FGF3 increased the percentage of S-phase cells and decreased the ratio of G0/G1 phase cells compared with the control. By contrast, cells treated with FGF3 plus FP16

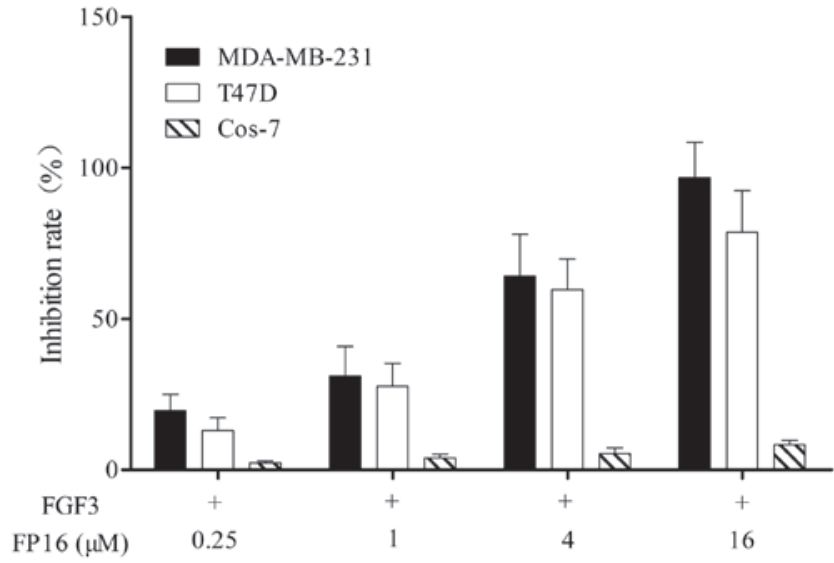

Figure 2. Effects of synthetic FP16 peptides on FGF3-stimulated cell proliferation. The cells were starved for $24 \mathrm{~h}$ and then treated with $50 \mathrm{ng} / \mathrm{ml}$ FGF3 alone or $50 \mathrm{ng} / \mathrm{ml} \mathrm{FGF3} \mathrm{plus} \mathrm{FP16} \mathrm{at} \mathrm{the} \mathrm{indicated} \mathrm{concentrations.}$ Cells without treatment of FGF3 or FP16 were used as the control. Cell proliferation was determined $48 \mathrm{~h}$ after treatment. Inhibition ratio $=\left[\left(\mathrm{OD}_{\mathrm{FGF}^{3}}-\mathrm{O}\right.\right.$ $\left.\left.\mathrm{D}_{\text {control }}\right)-\left(\mathrm{OD}_{\mathrm{FGF} 3}-\mathrm{OD}_{\mathrm{FGF} 3}+\mathrm{FP16}\right)\right] /\left(\mathrm{OD}_{\mathrm{FGF} 3}-\mathrm{OD}_{\text {control }}\right)$. Data are presented as the mean \pm standard deviation of triplicate samples. FGF3, fibroblast growth factor 3 .

presented a higher G0/G1-phase population and a decreased S-phase population compared with those treated with FGF3 alone. These results suggest that FP16 specifically inhibits FGF3-stimulated cell proliferation by arresting the cells at the G0/G1 phase.

It has been reported that cyclin D1 is a G1/S-specific regulating protein that controls cell cycle progression. The active cyclin D1-CD4/6 complexes release E2F transcription factors and induce specific gene expression required for G1- to S-phase progression (15). The effect of FP16 on the expression of cyclin D1 was determined by western blot analysis. The results shown in Fig. 4 indicate that FGF3 significantly increased the expression of cyclin D1 in MDA-MB-231 and T47D cells, whereas pretreatment with $\mathrm{P} 12$ peptides prior to stimulation with FGF3 led to a significant decrease in the expression of cyclin D1, suggesting that the mechanisms by which FP16 
A
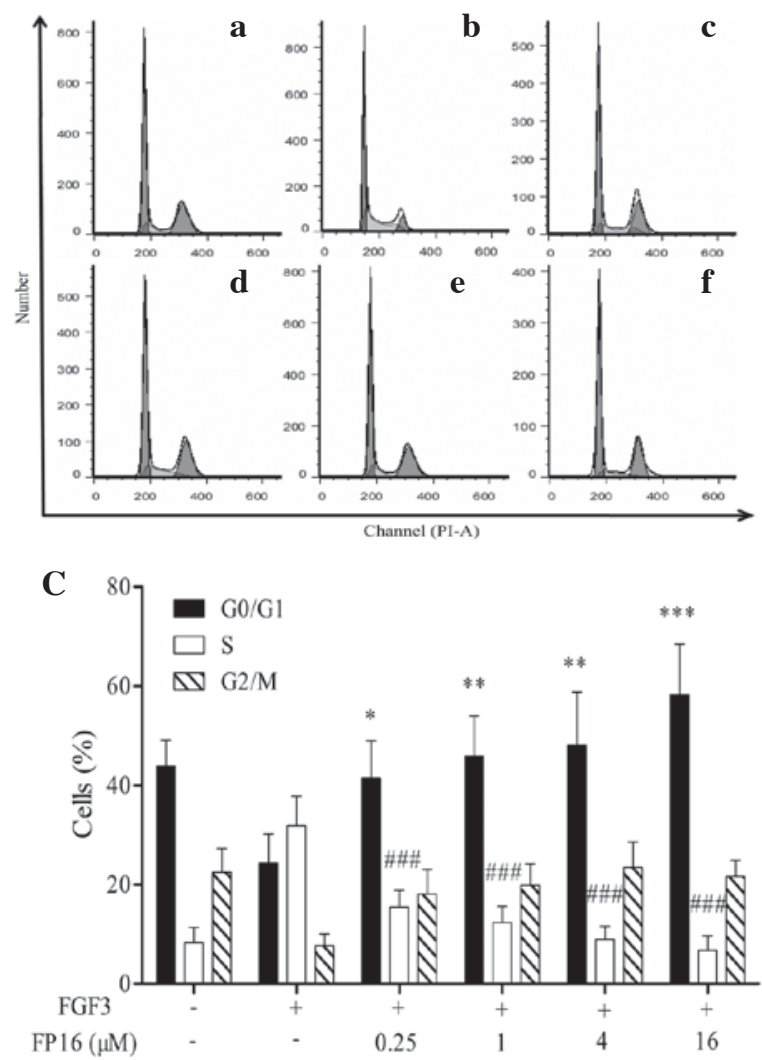

B
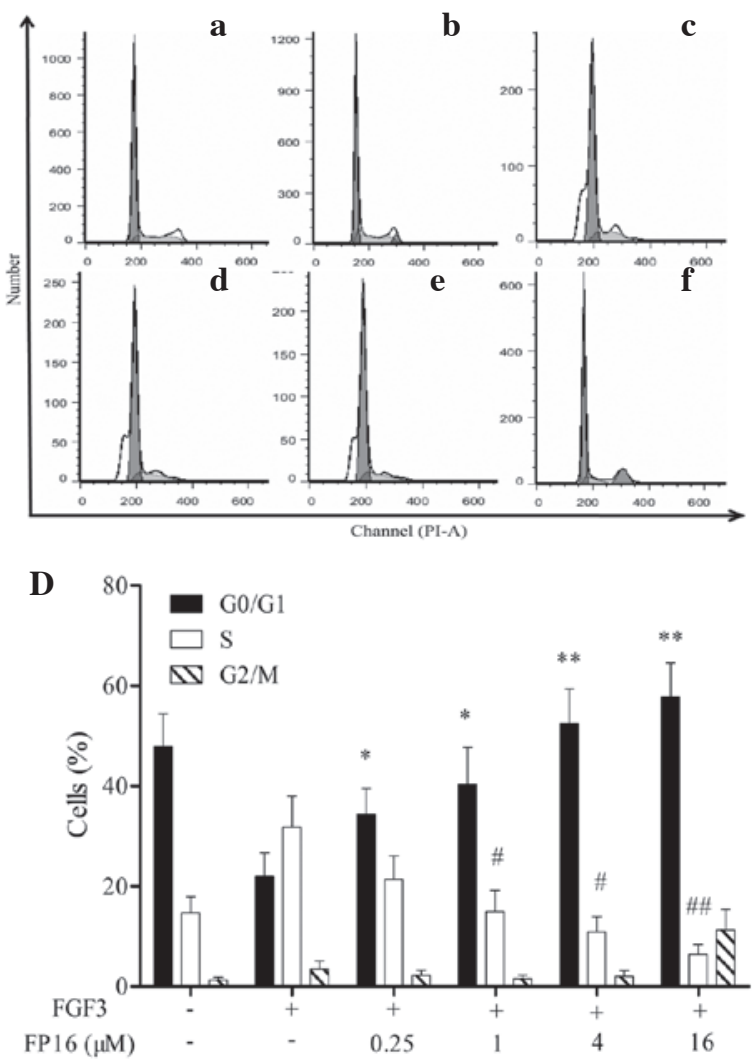

Figure 3. Flow cytometric analysis of the effect of FP16 on cell cycle distribution of FGF3-stimulated MDA-MB-231 and T47D cells. (A) MDA-MB-231 cells and (B) T47D cells. (a) Control cells without treatment of FGF3 or FP16. Cells were starved for $24 \mathrm{~h}$ and then treated with (b) 50 ng/ml FGF3 or 50 ng/ml FGF3 plus various concentrations of FP16, including (c) 0.25 , (d) 1 , (e) 4 and (f) $16 \mu \mathrm{M}$ for $48 \mathrm{~h}$. (C and D) Cell cycle distribution of the control and treated MDA-MB-231 and T47D cells. ${ }^{*} \mathrm{P}<0.05,{ }^{* *} \mathrm{P}<0.01,{ }^{* * *} \mathrm{P}<0.001$ vs. FGF3 group in G1/G0 phase; ${ }^{\#} \mathrm{P}<0.005,{ }^{\# \#} \mathrm{P}<0.01,{ }^{\# \# \#} \mathrm{P}<0.001$ vs. FGF3 group at $\mathrm{S}$ phase. Data are presented as the mean \pm standard deviation of triplicate samples. FGF3, fibroblast growth factor 3 .

A

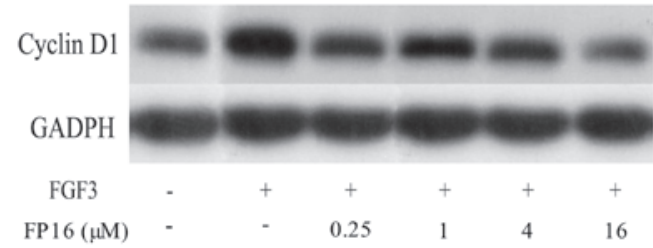

B
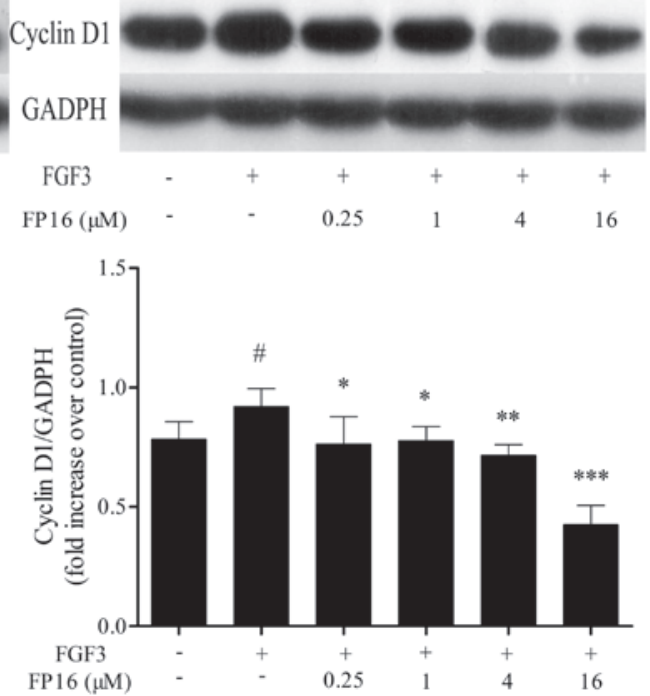

Figure 4. Synthetic FP16 peptides counteracted the regulatory effect of FGF3 on cyclin D1. (A) MDA-MB-231 cells and (B) T47D cells were starved for 24 h and then treated with $50 \mathrm{ng} / \mathrm{ml} \mathrm{FGF3}$ or $50 \mathrm{ng} / \mathrm{ml} \mathrm{FGF3} \mathrm{plus} \mathrm{various} \mathrm{concentrations} \mathrm{of} \mathrm{FP16} \mathrm{for} 6$ h. Cells without treatment of FGF3 or FP16 were used as the control. Sample loadings were controlled by GAPDH protein quantification. ${ }^{\#} \mathrm{P}<0.005,{ }^{\#} \mathrm{P}<0.01$ vs. the control group; $\mathrm{P}<0.05$, ${ }^{* *} \mathrm{P}<0.01,{ }^{* * * *} \mathrm{P}<0.001 \mathrm{vs}$. the FGF3 group. Data are presented as the mean \pm standard deviation of triplicate samples. FGF3, fibroblast growth factor 3.

peptides arrest cells at the G0/G1 phase may partially be through downregulation of the expression of the G1/S-specific protein cyclin D1.
Synthetic FP16 peptides inhibit FGF3-induced phosphorylation of Akt and MAP kinases. The tyrosine kinase-activated Ras/MEK/Erk pathway and the Ras/PI3K pathway have 

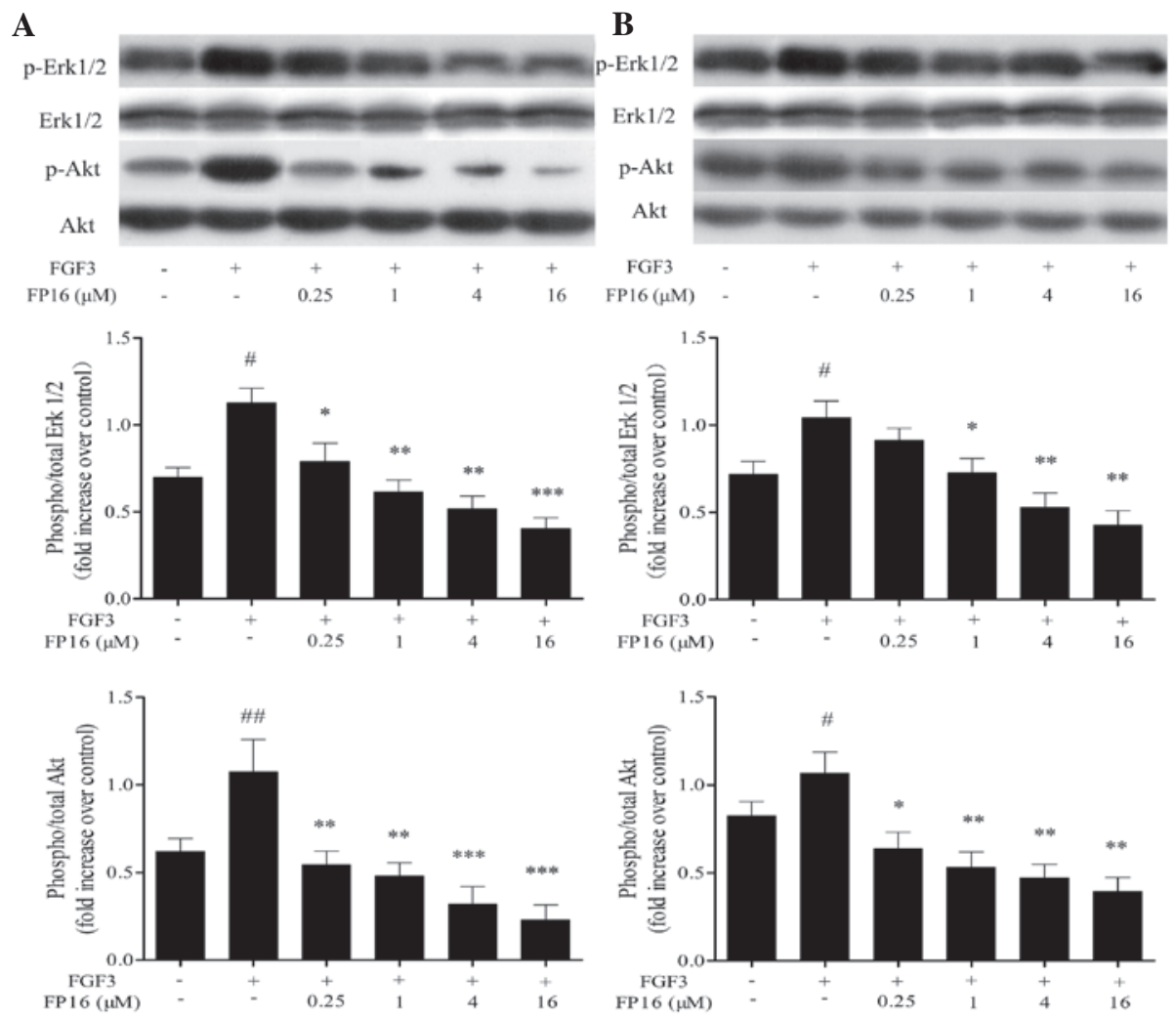

Figure 5. Synthetic FP16 peptides inhibit FGF3-induced Erk1/2 and Akt activation. (A) MDA-MB-231 cells and (B) T47D cells were pretreated with FP16 at the indicated concentrations for 30 min prior to stimulation with $50 \mathrm{ng} / \mathrm{ml} \mathrm{FGF3} \mathrm{for} 3 \mathrm{~h}$. Cells without treatment of FGF3 or FP16 were used as the control. Density ratios of phosphorylated proteins to total proteins were presented as the mean \pm standard deviation of three independent experiments. ${ }^{\prime \prime} \mathrm{P}<0.005$, ${ }^{\# \#} \mathrm{P}<0.01$ vs. control group; ${ }^{*} \mathrm{P}<0.05,{ }^{* *} \mathrm{P}<0.01,{ }^{* * *} \mathrm{P}<0.001$ vs. FGF3 group. FGF3, fibroblast growth factor 3 .

A

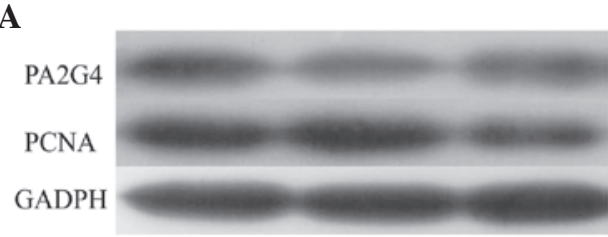

B

PA2G4

PCNA

GADPH

FGF3

$\mathrm{FP} 16(\mu \mathrm{M})$

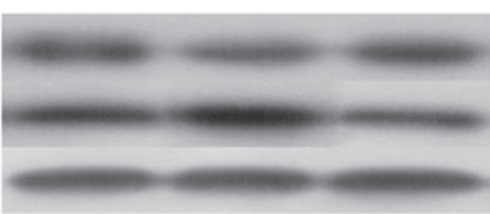

FGF3

FP16 $(\mu \mathrm{M})$
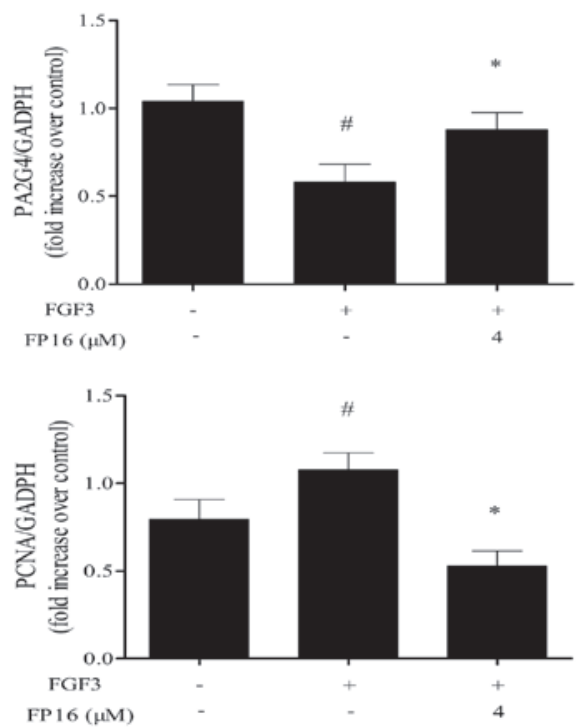
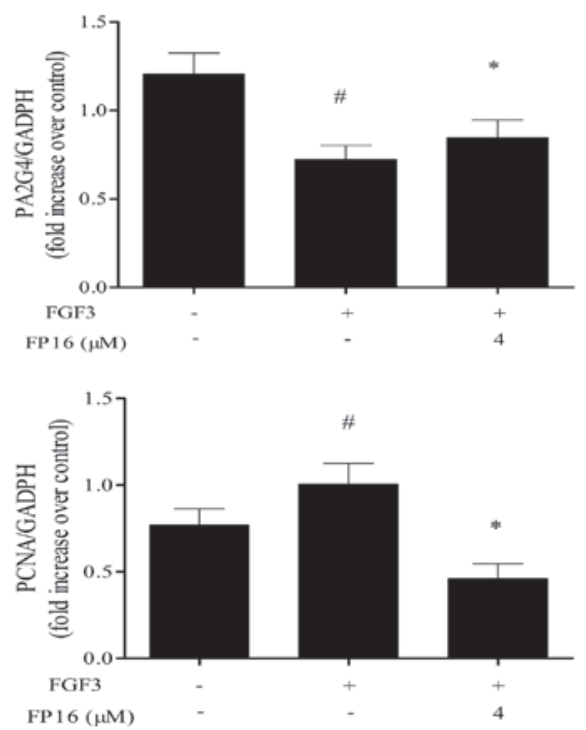

Figure 6. Synthetic FP16 peptides counteracted the regulatory effect of FGF3 on the expression of PA2G4 and PCNA. (A) MDA-MB-231 cells and (B) T47D cells were starved for $24 \mathrm{~h}$ and then treated with $50 \mathrm{ng} / \mathrm{ml}$ FGF3 alone or $50 \mathrm{ng} / \mathrm{ml} \mathrm{FGF3} \mathrm{plus} 4 \mu \mathrm{M}$ FP16 for $48 \mathrm{~h}$. Sample loading was controlled by GAPDH protein quantification. ${ }^{~} \mathrm{P}<0.05$ vs. control group; " $\mathrm{P}<0.05$ vs. FGF3 group. Data are presented as the mean \pm standard deviation of triplicate samples. FGF3, fibroblast growth factor 3; PCNA, proliferating cell nuclear antigen; PA2G4, proliferation-associated protein 2G4. 
a pivotal role in cell proliferation by regulating cyclin D1 expression in the middle of the G1 phase, and by driving cells past the G1-restriction point (16). In order to examine the potential of FP16 in cancer treatment, the present study further investigated the effects of FP16 on MAPK and Akt signal transduction in MDA-MB-231 and T47D cells. As shown in Fig. 5, exogenous FGF3 significantly stimulated the phosphorylation of Erk1/2 and Akt, while pretreatment of the cells with various concentrations of FP16 $(0.25-16 \mu \mathrm{M})$ for 30 min prior to stimulation with FGF3 resulted in significant inhibition of the activation of these signaling molecules in a dose-dependent manner. Taken together, these observations suggest that FP16 could irreversibly suppress FGF3-induced activation of MAPK and Akt.

FP16 counteracts the regulatory effect of FGF3 on PA2G4 and PCNA expression. It has been reported that PA2G4 is a cellular proliferation-inhibited DNA-binding protein, which can inhibit the proliferation and induce the differentiation of human breast cancer cells (17). PCNA is known as a DNA polymerase accessory protein involved in DNA replication, DNA repair and cell cycle control, and is considered to be a marker of cell proliferation in various types of cancer (18). In order to determine whether FP16 inhibited FGF3-stimulated cell proliferation by affecting PA2G4 and PCNA signal transduction, western blot analysis was performed. As shown in Fig. 6, PA2G4 expression was downregulated by FGF3 stimulation and enhanced by FP16 treatment, whereas FP16 treatment downregulated the expression of PCNA induced by FGF3, suggesting that PA2G4 and PCNA have an important role in how $\mathrm{P} 12$ peptides counteract FGF3-stimulated proliferation in MDA-MB-231 and T47D cells.

\section{Discussion}

Drug-resistant metastatic tumors and side effects are major limitations of conventional cancer therapy, including irradiation and chemotherapy (19), necessitating the search for novel tumor-targeting agents. Phage display technology provides an efficient tool to identify the desirable sequences binding specifically to targets, and has been widely used in diagnostic and therapeutic protein developments in previous years $(20,21)$. These small molecules, which are characterized from phage display libraries, exhibit great efficiency in penetrating into the targeted sites with low immunogenicity (22) and high concentration and validity (23). FGF/FGFR complexes have been demonstrated to act as driving oncogenes in certain types of cancer to maintain the malignant properties of tumor cells in a cell autonomous manner (24). Accumulating studies have demonstrated that FGF3 is upregulated in breast cancer and accelerates tumor growth and angiogenesis (10,25-27). Therefore, FGF3 has been considered as a potential target for breast cancer therapy.

In the present study, a phage-displayed heptapeptide library was used for identifying FGF3-binding peptides antagonists and the conditions of the selection were strictly limited to enrichment specific FGF3-binding phages. Following four rounds of panning, FP16 demonstrated a significantly positive signal and exhibited the strongest binding according to ELISA. In addition, FP16 peptide has four amino acids identical to the ligand-binding motif in D2 of FGFR2. Thus, it is reasonable to hypothesize that FP16 may have the capability to bind FGF3 and inhibit the biological activity of FGF3 by interrupting its interactions with FGFR2.

Cell proliferation is regulated during the G0/G1 phase in the cell cycle. Cyclin-dependent kinase (CDK) 4 and CDK6 interacting with the cyclin D family of proteins drive G0/G1 phase into the DNA synthesizing S-phase. The active cyclin D1-CD4/6 complexes release E2F transcription factors and motivate the specific gene expression required for G1 to S phase progression (28). The results of an MTT assay demonstrated that FP16 was effective in inhibiting MDA-MB-231 and T47D cell proliferation in a dose-dependent manner, while FP16 partially suppressed the growth of Cos-7 cells that do not express FGFRs. Furthermore, the results revealed that FP16 arrested FGF3-stimulated cells at the $\mathrm{G} 0 / \mathrm{G} 1$ phase and downregulated the expression of cyclin D1 and PCNA induced by FGF3. These data indicate that FP16 may inhibit FGF3-stimulated cell proliferation by restricting FGF3-induced G1 to $\mathrm{S}$ phase progression and downregulating the expression of $\mathrm{G} 1 / \mathrm{S}$-specific proteins cyclin D1 and PCNA.

The tyrosine kinase-activated Ras/MEK/Erk pathway and Ras/PI3K pathway are important in cell proliferation by regulating cyclin D1 expression during mid-G1 and driving cells past the G1-restriction point (29). It has been reported that PA2G4 inhibits the proliferation and induces the differentiation of human breast cancer cells (17). Western blot analysis demonstrated that AP8 suppressed FGF3-induced Erk1/2 and Akt phosphorylation in a dose-dependent manner, while increasing PA2G4 expression in MDA-MB-231 and T47D cells. It is reasonable to hypothesize that FP16 may have counteracted FGF3-stimulated proliferation and the cell cycle by inhibiting activation of MAPK and Akt, increasing PA2G4 expression and suppressing the expression of cyclin D1 and PCNA.

In conclusion, an FGF3-binding peptide FP16 was successfully screened from a phage display heptapeptide library. It was found that FP16 can counteract FGF3-stimulated proliferation and the cell cycle by inhibiting activation of MAPK and Akt, increasing PA2G4 expression and suppressing the expression of cyclin D1 and PCNA. Thus, FP16 may have potential application for the treatment of various types of cancer, including breast cancer, characterized by the upregulation of FGF3/FGFRs.

\section{Acknowledgements}

This study was supported by the City and academy cooperation projects of Foshan (grant no. 2012HY100611); the major National Science and Technology project: Major infectious diseases such as AIDS and Viral Hepatitis Prevention and treatment in the area of Baoan district; Shenzhen and Panyu district of Guangzhou (project no. 2012ZX10004903); and the research on the Nanotechnology-based Diagnostics of interleukin-22 (project no. 2014ZX10003002-003). This study was edited and modified by the English Language Service. 


\section{References}

1. Beenken A and Mohammadi M: The FGF family: Biology, pathophysiology and therapy. Nat Rev Drug Discov 8: 235-253, 2009.

2. Mohammadi M, Olsen SK and Ibrahimi OA: Structural basis for fibroblast growth factor receptor activation. Cytokine Growth Factor Rev 16: 107-137, 2005

3. Rusnati M and Presta M: Fibroblast growth factors/fibroblast growth factor receptors as targets for the development of anti-angiogenesis strategies. Curr Pharm Des 13: 2025-2044, 2007.

4. Saxena R and Dwivedi A: ErbB family receptor inhibitors as therapeutic agents in breast cancer: Current status and future clinical perspective. Med Res Rev 32: 166-215, 2012.

5. Siegel R, Naishadham D and Jemal A: Cancer statistics, 2013. CA Cancer J Clin 63: 11-30, 2013.

6. Yamamoto M, Hosoda M, Nakano K, et al: p53 accumulation is a strong predictor of recurrence in estrogen receptor-positive breast cancer patients treated with aromatase inhibitors. Cancer Sci 105 81-88, 2014.

7. Choi SY, Chang YW, Park HJ, Kim HJ, Hong SS and Seo DY: Correlation of the apparent diffusion coefficiency values on diffusion-weighted imaging with prognostic factors for breast cancer. Brit J Radiol 85: E474-E479, 2012.

8. van de Vijver MJ: Molecular tests as prognostic factors in breast cancer. Virchows Arch 464: 283-291, 2014.

9. Donegan WL: Tumor-related prognostic factors for breast cancer. CA Cancer J Clin 47: 28-51, 1997.

10. Dickson C, Spencer-Dene B, Dillon C and Fantl V: Tyrosine kinase signalling in breast cancer: Fibroblast growth factors and their receptors. Breast Cancer Res 2: 191-196, 2000.

11. Grose R and Dickson C: Fibroblast growth factor signaling in tumorigenesis. Cytokine Growth Factor Rev 16: 179-186, 2005.

12. Ibrahimi OA, Zhang F, Eliseenkova AV, Itoh N, Linhardt R. and Mohammadi M: Biochemical analysis of pathogenic ligand-dependent FGFR2 mutations suggests distinct pathophysiological mechanisms for craniofacial and limb abnormalities. Hum Mol Genet 13: 2313-2324, 2004.

13. Penault-Llorca F, Bertucci F, Adélaïde J, Parc P, Coulier F Jacquemier J, Birnbaum D and deLapeyrière O: Expression of FGF and FGF receptor genes in human breast cancer. Int J Cancer 61 170-176, 1995.

14. Wu XP, Huang HX, Wang C, Lin S, Huang Y, Wang Y, Liang G, Yan Q, Xiao J, Wu J, et al: Identification of a novel peptide that blocks basic fibroblast growth factor-mediated cell proliferation. Oncotarget 4: 1819-1828, 2013.
15. Fu M, Wang C, Li Z, Sakamaki T and Pestell RG: Minireview: Cyclin D1: Normal and abnormal functions. Endocrinology 145: 5439-5447, 2004.

16. Pagès G, Lenormand P, L'Allemain G, Chambard JC, Meloche S and Pouysségur J: Mitogen-activated protein kinases p42mapk and p44mapk are required for fibroblast proliferation. Proc Natl Acad Sci USA 90: 8319-8323, 1993.

17. Xia X, Cheng A, Lessor T, Zhang Y and Hamburger AW: Ebp1, an ErbB-3 binding protein, interacts with $\mathrm{Rb}$ and affects $\mathrm{Rb}$ transcriptional regulation. J Cell Physiol 187: 209-217, 2001.

18. Maga $\mathrm{G}$ and Hubscher U: Proliferating cell nuclear antigen (PCNA): A dancer with many partners. J Cell Sci 116: 3051-3060, 2003.

19. Zhang JT and Liu Y: Use of comparative proteomics to identify potential resistance mechanisms in cancer treatment. Cancer Treat Rev 33: 741-756, 2007.

20. Kandel E: Tumor-associated oncogenes go on (phage) display. Oncotarget 1: 84-85, 2010.

21. Ionov Y: A high throughput method for identifying personalized tumor-associated antigens. Oncotarget 1: 148-155, 2010.

22. Bae DG, Kim TD, Li G, Yoon WH and Chae CB: Anti-Flt1 peptide, a vascular endothelial growth factor receptor 1-specific hexapeptide, inhibits tumor growth and metastasis. Clinical Cancer Res 11: 2651-2661, 2005.

23. Yardley DA, Hart L, Bosserman L, Salleh MN, Waterhouse DM, Hagan MK, Richards P, DeSilvio ML, Mahoney JM and Nagarwala Y: Phase II study evaluating lapatinib in combination with nab-paclitaxel in HER2-overexpressing metastatic breast cancer patients who have received no more than one prior chemotherapeutic regimen. Breast Cancer Res Treat 137: 457-464, 2013.

24. Knights V and Cook SJ: De-regulated FGF receptors as therapeutic targets in cancer. Pharmacol Ther 125: 105-117, 2010.

25. Li Y, Hively WP and Varmus HE: Use of MMTV-Wnt-1 transgenic mice for studying the genetic basis of breast cancer. Oncogene 19: 1002-1009, 2000.

26. Turnbull C, Ahmed S, Morrison J, et al: Genome-wide association study identifies five new breast cancer susceptibility loci. Nat Genet 42: 504-547, 2010.

27. Roy D and Calaf GM: Allelic loss at chromosome 11q13 alters FGF3 gene expression in a human breast cancer progression model. Oncol Rep 32: 2445-2452, 2014.

28. Sherr CJ: G1 phase progression: Cycling on cue. Cell 79: 551-555, 1994.

29. Welsh CF, Roovers K, Villanueva J, Liu YQ, Schwartz MA and Assoian RK: Timing of cyclin D1 expression within G1 phase is controlled by Rho. Nat Cell Biol 3: 950-957, 2001. 